\title{
Infantile Refsum Disease
}

National Cancer Institute

\section{Source}

National Cancer Institute. Infantile Refsum Disease. NCI Thesaurus. Code C84789.

A genetic disorder characterized by abnormalities in the breakdown of phytanic acid. It results in accumulation of phytanic acid in the blood, brain and other tissues. Signs and symptoms include retinitis pigmentosa which may lead to blindness, hearing problems and deafness, hypotonia, ataxia, nystag mus, facial deformities, and mental and growth retardation. 